\title{
Analysis and Design of Main Roles in Educational Games about Forestry Basic Knowledge
}

\author{
Min Qiu, Ruigai Li, MingSheng Chen
}

College of Information and Computer Engineer, Northeast Forestry University, Harbin, China.

Email: 2362695085@qq.com, Lirg751@163.com,584965461@qq.com

Received 2013

\begin{abstract}
With the progress of the game production technology, educational games become a developing trend in the field of education. As the soul of the game, the role of the game to a large extent influences the effect of educational games. This paper details the analysis and design process of roles about forestry basics educational games. According to the various elements of the project needs and virtual environments, ultimately the roles are divided into the main role, assisted role and the role of attack, and detailed design for all kinds of roles.
\end{abstract}

Keywords: Educational Game; Character Analysis; Role Design

\section{Introduction}

Educational game is an electronic game both game features and educational function. Through the game educational background structure virtual scenarios and design plot. Excellent educational games need to balance the relationship between the education and entertainment. Answer questions from the respective disciplines in the course of play, players score and clearance, and ultimately achieve the purpose of growth in the knowledge of the play process. Therefore, the role of educational games and plot design is to determine a key part of the quality of the game. The distinctive appearance of the unique role and realism, fascinating story attracted many players of all ages and sought after.

This article relying on Project 2012 annual national Undergraduate innovative projects” Interactive Forestry basics learning software design". Aims to design a learning software of forestry basics. Mainly based on the characteristics of the various forest ecosystems, such as the use of the biological characteristics of the dominant tree species to design game characters and design the virtual environment of the game based on the principles of landscape design. In the course of the game players understand forestry basics, Enhance feelings of the forest ecosystems internal various biological, cultivate forest protection awareness and achieve harmony with nature. Game software design can attract young people to the forest science and other related fields and even love, and think of forestry development and the country's future sustainable development.

\section{The Type of Game}

With the vigorous development of the game industry, the game has become another hot topic of today's society, flooded with a wide variety of games in front. Today's main game type the following five ${ }^{[1]}$ :

(1)Action Game: Players to control game characters with a variety of weapons to destroy. (2)Simulation Game: The players use the strategy with the computer or other players contest to obtain various forms victory.

(3)Real-Time Strategy Game: The players in the game in order to achieve victory, we must stop operating, because the "enemy" is also engaged in similar operations.

(4)Music Game: In order to develop the players of the music sensitivity, and enhance music perception.

(5) Role Playing Game: In the game players play one or several roles, and It has the complete story, emphasis on plot development and personal experience, with upgrades and skills growth factor. It is the most popular game types.

Role Playing Game is characterized by its coherent plot as clues. Players will experience the story as the hero in the play. In order to fully understand the plot or the completion of the production design goals the players must follow the story as it develops. The meantime will interspersed with some of the obstacles or tasks, players only crack all obstacles in order to achieve the ultimate goal. The greatest advantage of this model is to make the players have a real sense of the experience in the virtual world, game designers also stay out of the endless imagination. Therefore, the game use RPG game mode to design. The Forestry Knowledge is arranged the film's 
plot legitimately and interestingly. The players have the desire to acquire knowledge, and thus achieve the purpose of the course.

\section{Classification of Role and Positioning of Game}

As the soul of the game, roles not only throughout the game's plot the whole way and play a very important role in the game, but also is what players concerned about. How to shape a charming, impressive role is the key of design a successful game ${ }^{[2]}$. The game as a purpose to promote the forestry knowledge of RPG game, according to the project requirements and forest ecological characteristics extraction results for game design, the game's main role is divided into the following two types:

(1)PC (Player Character), players control role, is players responsible for controlling the debut figures. For the players, the role of the sense of identity is very important, the virtual character of the players in the game.

(2)NPC (Non Player Character), non-player control a character, commonly known as a passerby. The main role is to interact with the players, including the account of tasks, provide clues powerful BOSS. This project there are two mainly kinds of NPC characters: assisted NPC and attack NPC.

Different types of games decided positioning and style of the game character, the project belongs to the Forestry basics class educational games, in the role design process, the main idea of designing is based on role appearance, personality characteristics, identity, artistic style, and many other aspects of the game character design, design style highlights the natural style, realistic ${ }^{[3]}$. Character design from the following aspects:

Appearance--We do our utmost to integrate natural elements into the appearance design of actors. Such as the design of a tree wizard, the tree trunk made into its body, leaves abstract as hair.

Physical characteristics-- Designed in accordance with the habits of the animal and plant itself character. The major aggressor image wolf brutal werewolves design into bloody ferocious. Designed according to the characteristics of the banyan tree age long figure who trained, intelligent image of aging and so on.

Identity-- The identity of the various roles designed according to the principle of living things in nature allelopathy. Strangling vine attached to the trees grow, and eventually kill the host, so I designed it as the image of the monster.

Artistic style-- The role artistic style divided into the type of cute, realistic, and extrasensory. Considered out of the game background and game types, the main game character design cartoon realism type.

\section{Design and Implementation of Main Roles of Game}

Excellent game role is the role of the high reliability, enabling players to produce immersive personal experience $^{[4]}$. Major roles and their characteristics are as follows:

\subsection{Hero}

Name: Ling Che Gender: $\mathrm{M} \quad$ Age: 18

Physical characteristics: The boy looks handsome, tall and handsome. Ling Che's clothing, ordinary style, but compact design, and is very consistent with the public aesthetic. The clothing detail design delicate, such as linen clothes, shoulders fur, the right hand with the archery with the armband gloves, and belt patterns, maximize reflects his growing environment and identity.

Story background: Ling Che had grown up in a small mountain village, together with his father practicing medicine. The way once herbs in the mountains, Ling Che unfortunately hit by torrential rain, trapped in the mountains more than half. Unexpectedly, he goes down, to see the village littered with corpses. Original over the years the villagers do not know how to maintain the ecological balance, and wantonly destroying the ecology. Finally they were punished by nature. Ling Che took the ancestral prescription, determined to find a cure, to save the people.

Character attributes: Character level in the game is divided into three. Hero increase wealth and experience through finishing the task, and supplementary items in the backpack.

Tasks Classification: The main task is divided into adventure and access. Adventure tasks include exploration and beat monsters. Access tasks are competitive answer of forestry basics. The degree of difficulty of the task increases as the level increased.

Physical value: Each level are the initial physical values, normal walking, complete the task process, combat process will consume different physical values, when the physical value is too low, he cannot carry out the task, when death is equal to zero. Through the normal supply of food and drugs can enhance physical strength values.

Health value: Each level are the initial health value, under normal circumstances don't consume health value, when encounter attack healthy consumption values, such as consumption was bitten by a pig monster, hurt by tree strange poison consume two points. When the health value too low cannot carry out the task, zero death, through the drug can promote health values.

Wealth value: can be provided through the system of small tasks to earn gold, use coins to buy ordinary food, drug, experience and weapons and equipment, etc.

\subsection{Assisted NPC}

The assisted NPC roles that designed for this system mainly extract representative species with little ATK 
from various forest ecosystem, such as arbor, shrub, and precious herbal. According to their ecological habits, it designs the assisted NPC roles, such as Banyan tree fairy, small Ginseng goblin, Blueberry elves, small Schisandra elves, Bamboo sister Manchurian ash grandfather and so on. They don't have ATK, as the assisted roles of the system, they mainly have the function which can interact with the players, including explain the task, provide clues, answer difficulties and so on. Some assisted roles and their features are as follows.

- Banyan Tree Fairy

Appearance characteristics: The lush treetop turns into the brain full of wisdom. According to its "one tree becomes forest" character, its plate-like root turn into the beard and the beard can stretch as the weapon to attack enemies. At the same time, according to the character of its longevity, it is designed as a wise man. The light of wisdom is always flashing in its eyes.

Appearance Background: The clever and big banyan tree will appear as a role which can assist the adventure of protagonist. When the protagonist goes through some unsolvable problems in the adventure, he can consult the clever banyan tree, but the protagonist need gain definite wealth in return. At the same time, it also can become a role as the existence of conveying knowledge for us.

\section{- Fish Elves}

Appearance characteristics: For the overall image of fish, the place in detail do some exaggerated. Such as huge colorful fish, clever eyes, etc . In a word, fish elves give a person a kind of a group of lively and lovely children feeling.

Appearance Background: Fish fairy appeared in the lakes, the hero help fish elves to complete the task, they reach the shore hint hero method.

The mode of "Mining lotus song" task is as follows.

The mode name: Mining lotus song. The level of task is One-level, the aid of task is help the fish elves find the lotus, gain the lonus and improve its magical power. The system will reward 20 values of wealth, 20 values of experience and the lonus which worth 50 coins.

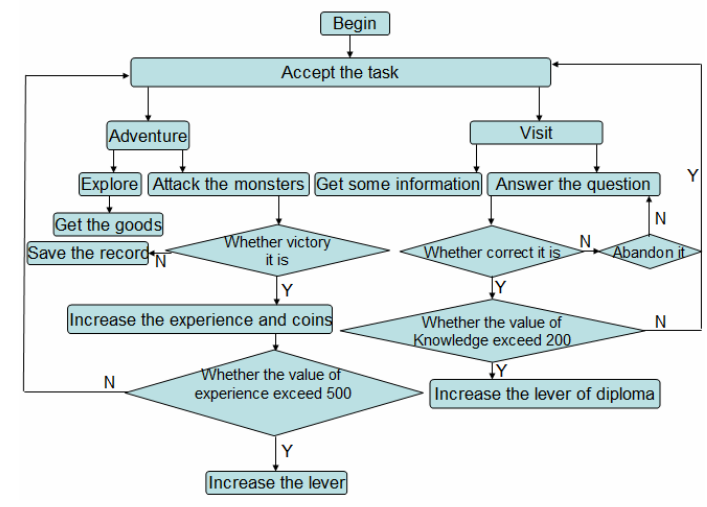

Figure 1. Program flow chart.

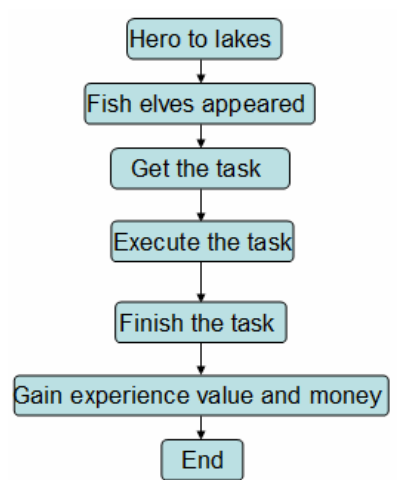

Figure 2. Auxiliary strategy flow chart.

Main dialog is as follows.

Fish elves: I need lonus to improve my magical power, but because of the limit of area, I can't arrive there. If you can help me get the lonus, I will give you some reward in return.

Protagonist: OK, I will help you get the lonus.

\subsection{Assisted NPC}

The offensive NPC roles that designed for this system mainly extract the plant and animal species with the offensive characteristics from the forest ecosystem. The roles are designed depend on ecological habits. There are werewolf, tiger goblin, cannibal tree goblin, flower monster and so on. They have attack power. As the offensive roles of the system, they mainly have these functions: attacking players, avoiding players to complete task and preventing players pass the checkpoints. Some offensive roles and their characteristics are as follows.

- Pig Monsters

Appearance Characteristics: It likes pig and also likes man, it has the sharp tusks , but it can walk as a man.

Appearance Background: The murderous and cruel pig monsters appear in the mountain when Ling Che looking for the elixir. The protagonist will meet with the pig monsters at the necessary road to mountain. As the guardian of the elixir, pig monsters don't allow anyone to encroach on the elixir. They spread cruel attack against Ling Che and pledge kill him at here. Ling Che struggles with the pig monsters without consider his life, he kill the pig monsters and pick up the elixir.

Human property: The value of life is 300 , the pig monsters will die when the value of life under 0 . Main methods are pig monsters tusks' attack. The attack success can let the protagonist's value of physical ability and health decreases 40 . The attack strategy of pig monsters is attacking the protagonist appear within 30 meters distance from pig monsters. The protagonist can get the elixir when he defeat the pig monsters, and he also can gain 80 values of wealth, 80 values of experience and the tusks of pig monster which worth 60 coins.(Figure 3) 


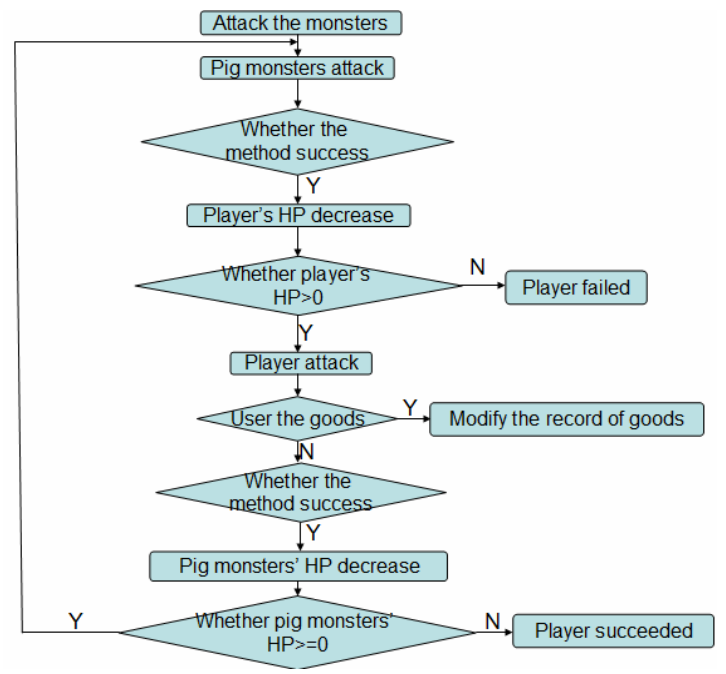

Figure 3. Attack strategy flow chart.

- $\quad$ Tree Monster

Appearance characteristics: Depending on the strangle rattan in nature, its main part is a huge tree. It can devour the things close to it by swinging its petals. At the same time, it can secrete poisonous mucus to poison the other living beings.

Appearance Background: The tree monster queens it over in the mountain. It destroys the zoology, even devours the elixir which Ling Che needs. Ling Che must kill the tree monster if he wants to get the elixir.

Attack Strategy: The tree attacks by crushing its head, swinging its leaves and twine its root. Once the enemies are twined by it, the tree monster will try its best to twine them body tightly till they die. The most terrible thing is the poison of the tree monster. Once the players touch it, they will appear some symptom, such as headache, lacking in strength, even lead to the value of health decrease quickly.

The design for the roles of this project uses the 3ds max products of American company which named as Autodesk as the main entertainment for design. In the proceeding of the design of roles, the project uses Photoshop CS5 of American company which named as Adobe as the assisted develop tools(Figure 4).

\section{Conclusion}

This paper describes the design of the game character. This game character design closely combining the purpose and meaning of the game. Design the game of virtual environment and the experience of the main characters. Auxiliary role type designed according to the characteristics of the virtual environment and the elements properties. Role in the design process takes into account various factors. Whether it is clothing or behavior prophecy, it has his unique personality; players can easily distinguish and discern his identity. In order to make the
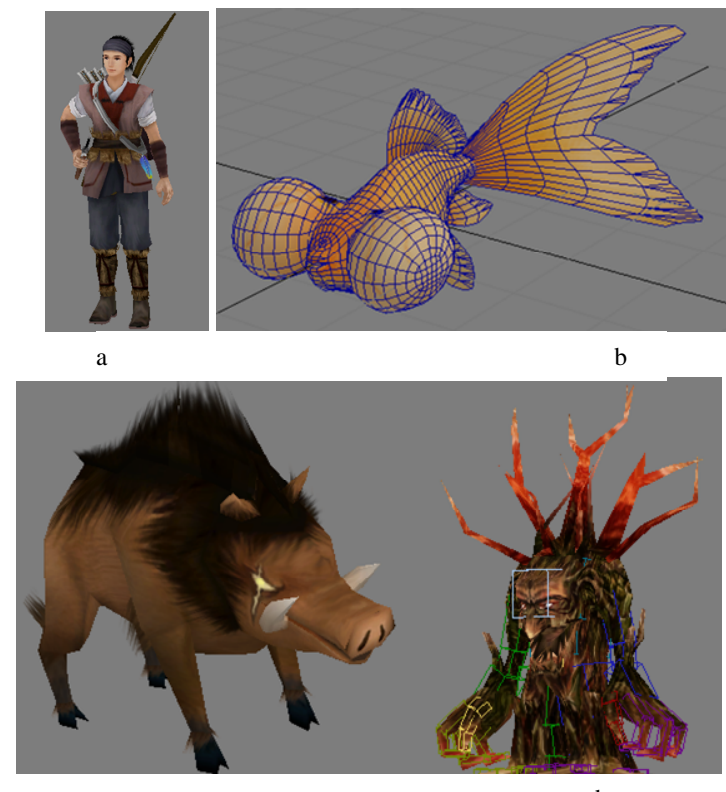

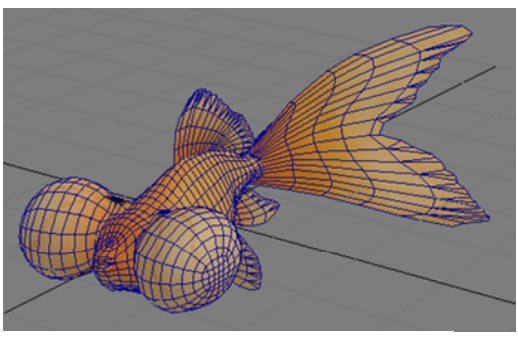

Figure 4. The roles of the gam e: (a) Hero Ling Che; (b) Fish elves; (c) Pig Monster; (d) Tree Monster.

role of the image of more fullness, this game for all kinds of characters is endowed with more plots and background of the story. Based on detailed analysis combined with the status of the corresponding technology enable the game to become a good educational game of forestry basics.

\section{Acknowledgment}

This paper is Supported by two projects:

(1)National Undergraduate Innovation Plans in 2012 (201210225064) : Design of Interactive Educational Software about Forestry Base Knowledge;

(2) The "Twelfth Five-Year" Planning Issues about Higher Education Scientific Research from Institute of Higher Education in Heilongjiang Province: (HGJXH C110420): The Empirical Study on the WebQuest \& CDIO Teaching Mode in the Teaching Practice.

\section{REFERENCES}

[1] Jim Thompson, Barbados than - Burbank Green, Nick • Fidel worth (A), Zhang Kaigong,the game design basis curriculum [M]. Shanghai: Shanghai People's Fine Arts Publishing House.2008.

[2] Yun Runwei, Dong Jie Network game planning tutorial [M]. Beijing: mechanical industry publishing house. 2009.

[3] Qi Jianghua The spirit of the game - discuss game character design $[\mathrm{J}]$. Science and technology information. 2009, 46-48.

[4] Jonathan S.Harbour, Chen Zheng, Fu Xin Introduction to game programming $[\mathrm{M}]$. Beijing: mechanical industry publishing house. 2009. 